all cases, only two spots could be demonstrated by spraying with a solution of $p$-dimethylaminobenzaldehyde. A very faint spot corresponded to 4-aminodiphenyl. This spot was strengthened when ether extracts of the urine were examined. The second more intense spot travelled at the same rate as 4-amino-3-diphenylyl hydrogen sulphate; hydrolysis of the urine by boiling with acid gave a new spot corresponding to 3-hydroxy-4-aminodiphenyl.

Urine from dogs fed benzidine (500 $\mathrm{mgm}$./day) was chromatographed on paper in ten solvent systems. Three major and a number of other spots were demonstrated with the $p$-dimethylaminobenzaldehyde spray. Benzidine and 4:4'-diamino-3-diphenylyl hydrogen sulphate were shown to be important metabolites of the amine. 3-Hydroxybenzidine was shown to be present as a minor metabolite in some samples of urine. The other metabolites have not yet been identified.

Continuous ether extraction of the urine of a dog fed benzidine (500 $\mathrm{mgm}$./day) for ten days enabled benzidine (400 mgm.; 8 per cent of the dose) and 3-hydroxybenzidine ( $85 \mathrm{mgm} ., 1.5$ per cent) to be isolated. The benzidine, melting point and mixed melting point $124^{\circ}$, was characterized as the $p$-toluenesulphonate, melting point $241-242^{\circ}$, mixed melting point $242-243^{\circ}$. The monohydroxybenzidine, melting point $180-183^{\circ}$, was characterized as its tribenzoate, melting point $269^{\circ}$, mixed melting point $270-271^{\circ}$.

This work will be reported in detail later. We wish to thank Dr. G. M. Bonser for making available the biological material.

L. BRADSHAW

Department of Experimental Pathology

D. B. Clayson

and Cancer Research,

School of Medicine.

University of Leeds. July 4.

${ }^{1}$ Clayson, D. B., Ann. Rep. Brit. Emp. Cancer Campaign, 29, 148 (1951); Brit. J. Cancer, 7, 460 (1953).

${ }^{2}$ Walpole, A. L., Williams, M. H. C., and Roberts, D. C., Brit. J. Indust. Med., 11, 105 (1954).

${ }^{3}$ Boyland, E., and Sims, P., J. Chem. Soc., 980 (1954).

\section{Synergism in the Chemotherapy of Eimeria tenella}

IN 1954, Lux ${ }^{2}$ investigated the possibility that potent inhibitors of Eimeria tenella might be found among compounds, other than sulphonamides, which interfered with the $p$-aminobenzoic acid - folic acid metabolic sequence. Lux found that a group of 2,4-diamino-pyrimidines possessed anticoccidial activity, one of the most active of the series being 2,4-diamino-5, $p$-chlorophenyl, 6-ethyl pyrimidine ('Pyrimethamine', 'Daraprim'). He noted, further. more, that this compound, when used in combination with certain sulphonamides, had a marked synergistic effect.

At Weybridge, we have extended these observations with the view of developing effective systems of chemotherapy for disease caused by Eimeria tenella. In the past, 'Sulphamezathine' (sulpha-dimethylpyrimidine) has in our experience proved most satisfactory for treatment under practical conditions; but its use can be criticized on the grounds that the concentration necessary to obtain a maximum therapeutic effect is sufficiently high to cause some degree of inappetence, that occasional toxicity is observed ${ }^{2}$, and that the full therapeutic concentration is liable to cause temporary inhibition of the parasite, develop. ment being merely delayed until treatment terminates $^{3,4}$. Our observations, which have confirmed those of Lux ${ }^{1}$, have shown that, although 0.01 per cent 'Daraprim' in the food affords only partial protection against $E$. tenella, the synergism between this substance and 'Sulphamezathine' permits the reduction of the concentration of both compounds to a fraction of that ordinarily needed for therapeutic control. Thus, in the presence of as little as 0.0025 per cent 'Daraprim' in the food, the concentration of 'Sulphamezathine' may be reduced to between $\frac{1}{8}$ and $\frac{1}{16}$ of that normally required for complete protection.

Temporary inhibition, with delayed clinical manifestations of disease, occurs with a mixture of 0.01 per cent 'Daraprim' and 0.05 per cent 'Sulphamezathine', but not when the concentration of 'Daraprim' in the mixture is reduced to 0.0025 per cent. This suggests that the combination of drugs at these low concentrations has a markedly selective effect on the later stages in the life-cycle of the parasite, leaving unimpaired the earlier stages, the development of which Kendall and McCullough ${ }^{8}$ have shown to be essential for effective chemotherapeutic control.

These findings are likely to be of marked practical importance, and it seems that the use of the synergistic combination will avoid the difficulties associated with the present use of the sulphonamides.

The synergistic action on E. tenella of 'Daraprim' and 'Sulphamezathine' can probably be explained as the effect of two antimetabolites which act sequentially at different stages in the same metabolic pathway, at the points at which $p$-aminobenzoic acid and folic and folinic acids are concerned.

This would suggest a close analogy between the metabolism of E. tenella and those species of Plasmodium on which 'Daraprim' and some sulphonamides also exert a marked synergistic effect ${ }^{5}$. $p$-Aminobenzoic acid has already been shown to be an essential metabolite for $E$. tenella by the observation of HortonSmith and Boyland' that the action of 'Sulphamezathine' may be antagonized by $p$-aminobenzoic acid. No facts are available on the importance of folic and folinic acids for E. tenella, although 'Daraprim' is regarded as an antagonist of folic and folinic acids in several other biological systems".

If, in fact, the metabolism of $E$. tenella is similar to that of the plasmodia, other anti-malarials may be able to replace 'Daraprim' in synergistic combination with sulphonamides or other drugs of known coccidiostatic value.

Studies on the above lines are proceeding.

L. P. JOYNER

S. Brian KENDALI

Ministry of Agriculture, Fisheries and Food

Veterinary Laboratory,

Weybridge.

July 18.

1 Lux, K. E., Antibiotics and Chemother., 4, 971 (1954).

${ }^{2}$ Davies, S. F. M., Proc. Tenth World Poultry Cong. Edin., 275 (1954).

${ }^{3}$ Kendall, S. B., and McCullough, F. S., J. Comp. Path., 62, 116 (1952). + Davies, S. F. M., and Kendall, S. B., J. Comp. Path., 64, 87 (1954). "Goodwin, L. G., and Rollo, I. M., in "Biochemistry and Physiology of Protozoa", 2 (edit. Hutner, S. H., and Lwoff, A., New York, 1955). Rollo, I. M., Brit. J. Pharmacol., 10, 208 (1955).

' Horton-Smith, C., and Boyland, E., Brit. J. Pharmacol., 1, 139 (1946).

7 Hitchings, G. H., Trans. Roy. Soc. Trop. Med. Hyg., 46, 467 (1952). 